\title{
Camp NERF: methods of a theory-based nutrition education recreation and fitness program aimed at preventing unhealthy weight gain in underserved elementary children during summer months
}

\author{
Laura C. Hopkins ${ }^{1}$, Mary Fristad ${ }^{2}$, Jacqueline D. Goodway ${ }^{3}$, Ihuoma Eneli ${ }^{4}$, Chris Holloman ${ }^{5}$, Julie A. Kennel', \\ Bernadette Melnyk ${ }^{7}$ and Carolyn Gunther ${ }^{8^{*}}$
}

\begin{abstract}
Background: The number of obese children in the US remains high, which is problematic due to the mental, physical, and academic effects of obesity on child health. Data indicate that school-age children, particularly underserved children, experience unhealthy gains in BMl at a rate nearly twice as fast during the summer months. Few efforts have been directed at implementing evidence-based programming to prevent excess weight gain during the summer recess.

Methods: Camp NERF is an 8-week, multi-component (nutrition, physical activity, and mental health), theory-based program for underserved school-age children in grades Kindergarten - 5th coupled with the USDA Summer Food Service Program. Twelve eligible elementary school sites will be randomized to one of the three programming groups: 1) Active Control (non-nutrition, physical activity, or mental health); 2) Standard Care (nutrition and physical activity); or 3) Enhanced Care (nutrition, physical activity, and mental health) programming. Anthropometric, behavioral, and psychosocial data will be collected from child-caregiver dyads pre- and post-intervention. Site-specific characteristics and process evaluation measures will also be collected.

Discussion: This is the first, evidence-based intervention to address the issue of weight gain during the summer months among underserved, school-aged children. Results from this study will provide researchers, practitioners, and public health professionals with insight on evidence-based programming to aid in childhood obesity prevention during this particular window of risk.
\end{abstract}

Trial Registration: NCT02908230/09-19-2016

Keywords: Nutrition, Physical activity, Elementary children, Behavioral intervention, Childhood obesity prevention

\section{Background}

While recent reports indicate a plateau in the rate of childhood obesity in the United States, the number of obese children remains high [1]. In 2011-2012, obesity affected $17 \%$ of US youth, with $31.8 \%$ being classified as overweight or obese [1]. Significant differences in prevalence of obesity exist between racial, ethnic and age groups. Non-

\footnotetext{
*Correspondence: gunther.22@osu.edu

${ }^{8}$ Department of Human Sciences, Human Nutrition Program, The Ohio State University, 313 Campbell Hall, 1787 Neil Avenue, Columbus, OH 43210, USA Full list of author information is available at the end of the article
}

Hispanic black and Hispanic youth are significantly more affected by obesity than their non-Hispanic White and non-Hispanic Asian peers [1]. Additionally, there appears to be a developmental trajectory in prevalence of obesity as $8 \%$ of 2 - to 5 -year olds, $17.7 \%$ of 6 - to 11 -year olds, and $20.5 \%$ of 12 - to 19 -year olds were classified as obese in 2011-2012 [1]. So while it appears that the rise in obesity has tapered off, the prevalence of overweight and obesity among US youth remains concerning due to its devastating consequences, which affect the physical and mental health of children, as well as their academic success [2,3]. 
Emerging research has begun to point to particular windows of risk for child weight gain. Troubling data indicate that school-age children experience unhealthy gains in BMI at a rate nearly twice as fast during the summer months when school is out of session compared to the school year [4-10]. African American and Hispanic, minority groups and economically disadvantaged children, subpopulations already at increased risk for obesity, as well as girls, may be particularly vulnerable to unhealthy weight gain during these non-academic months [1]. Limited knowledge of the external factors that lead to altered diet and physical activity during the summer time is available to adequately explain the unfavorable weight gain occurring in many children during this window of risk [11].

The rise and current status of obesity in the US has occurred at such a rapid rate that it cannot solely be attributed to biological changes [12]. While obesity rates have been rising over the past several decades, the US food environment has also been changing drastically, providing convenient access to an abundance of inexpensive, highly palatable, energy-dense foods [13]. Thus, the current prevalence of childhood obesity and demonstrated increase in obesity during the summer months could be a response to children's increased exposure to the food environment [13], which they have less frequent access to during the school year, and lack of structured physical activity. Schools play a critical role in promoting healthy diet and physical activity behaviors during the academic year [14]. During the summer months, however, children lose access to this structured environment (e.g., provision of healthy snacks and meals; opportunity for structured and unstructured physical activity; nutrition, physical activity, and health related policies and programs).

The United States Department of Agriculture (USDA) aims to provide access to healthy, nutritious meals to children during the summer months through the USDA Summer Food Service Program (SFSP) [15]. Unfortunately, attendance at USDA SFSP sites, especially open sites, and amount of meals served tends to be low. According to the Food Research Action Center, only $15.8 \%$ of free or reduced-cost school lunch participants received lunch in the summer of 2015 nationally [16]. In Ohio, only $10.8 \%$ of free or reduced-cost school lunch participants participated in the SFSP [17]. Several stakeholders have hypothesized that these low numbers are due to a lack of structured programming at the sites to attract children. Few efforts have been directed at designing evidence-based nutrition and physical activity programs to equip underserved children with the necessary knowledge, skills, and other resources to prevent excess weight gain during the summer recess.
Camp Nutrition Education Recreation and Fitness (NERF) is a multi-component, evidence-based nutrition, physical activity, and mental health intervention that is coupled with USDA SFSP open sites in Columbus, Ohio. To our knowledge, this is the first multi-component, evidence-based intervention to address the disproportionate childhood weight gain in underserved children during the summer months. The long-term goal is to develop and implement effective theory-based community nutrition and physical activity interventions for childhood obesity prevention, particularly in underserved minority children, aimed at empowering children to make healthy dietary and physical activity choices and achieve a healthy weight and, ultimately, overall optimal health and wellness. The primary aims of this research project are to:

1. Evaluate the efficacy of Camp NERF to improve child nutrition, physical activity, mental health, and anthropometric outcomes.

a. Hypothesis 1.1: Diet quality, physical activity and sedentary time, positive and negative affect, BMI z-scores, and waist circumference (WC) z-scores will improve more from baseline to postintervention among children participating at the Enhanced Care sites compared to Standard Care and Active Control sites.

2. Evaluate the efficacy of Camp NERF to improve caregiver self-efficacy for establishing healthy family nutrition and physical activity practices, amount of physical activity, and BMI.

a. Hypothesis 2.1: Caregiver self-efficacy scores for establishing healthy family nutrition and physical activity practices, physical activity score, and BMI will improve more from baseline to postintervention among families participating at the Enhanced Care sites compared to the Standard Care and Active Control sites.

3. Evaluate the efficacy of Camp NERF to improve youth mentor nutrition, physical activity, and anthropometric outcomes.

a. Hypothesis 3.1: Diet quality, physical activity and sedentary time, positive and negative affect, BMI z-scores, and waist circumference (WC) z-scores will improve among youth mentors from baseline to post-intervention.

\section{Methods}

\section{Camp NERF theoretical framework}

Commonalities among the relatively few successful community-based childhood obesity prevention efforts include: theoretical framework to the intervention, multi-component strategies, direct or indirect engagement of caregivers, and specific behavioral targets [18]. It has become widely accepted that use of a theoretical 
framework in the design of behavior change interventions is an essential ingredient for achieving positive outcomes. The Camp NERF intervention is guided by the social ecological model (SEM) and social cognitive theory (SCT) [19-21].

According to the socio-ecological framework, there is a complex interplay of factors at multiple levels of influence that determine a child's weight status, health, and wellness [22]. A child's risk for obesity is influenced by personal factors, such as genetics and diet and physical activity behaviors. These personal factors are, in turn, influenced by multiple external layers of influence including caregiver/ family practices and behaviors, environmental settings (home, school, community), various organizational sectors (education, government, public health, leisure, recreation), and social norms and values (societal rules that guide attitudes, beliefs, and behaviors, peer influence). The socioecological framework provides a theory-based approach to investigating the problem of childhood obesity and an understanding of the deep complexity of the etiology of this disease. It also serves as a useful tool in the design of theory-based behavior change interventions - and underlines the necessity in conducting cross-disciplinary research to effectively diminish the problem of childhood obesity.

The SCT broadly used among community nutrition researchers, proposes that behavior change results from a reciprocal relationship between personal and external factors [20]. An individual needs the personal resources to enact the desired behavior, which includes: knowledge and skills (ability to perform desired behavior); cognitive behavior techniques (goal-setting, problem solving, coping strategies); and self-efficacy (confidence in one's ability to enact the behavior). Regarding cognitive behavioral techniques, self-control is achieved via goal-setting. When goals are not achieved, alternative skills, such as problem solving and coping strategies can be employed to attain initial goals or set new, more achievable goals [20]. Also worth noting, children and adolescents who develop proficiency in general cognitive behavior techniques experience a sense of personal empowerment. In turn, this alleviates the mental health symptoms associated with overweight and obesity (poor self-concept and symptoms of anxiety and depression), leading to subsequent diet and physical activity related behavior change [23]. Cognitive behavior techniques are either vastly underdeveloped or missing from the curriculum of most childhood obesity prevention interventions [24, 25]. The Camp NERF intervention utilizes two evidence-based curricula that incorporate cognitive behavioral techniques - Coordinated Approaches to Child Health (CATCH) [26] and Creating Opportunities for Personal Empowerment (COPE) [27]. Additionally, goal-setting opportunities strategies are integrated into the Camp NERF curriculum and achievement of goals are tracked with goal-setting necklaces.
Under the SCT, environmental or external factors also play a part in determining behavior. With regards to child diet and physical activity behaviors, examples include: role modeling (caregivers, teachers, peers), availability of healthy meals and snacks, opportunity for indoor or outdoor physical activity and structure provided by daily routines [22]. Due to the complexity of behavior origination and change, the most efficacious interventions have been multi-component in design and included either direct or indirect caregiver engagement. As the nutritional gatekeepers of the household, caregivers play a major role in shaping the eating behaviors of their children and thus must be included as an intervention target [28]. Caregivers help children establish and reinforce target behaviors by role modeling intake of healthy foods, setting expectations for healthy food intake, and making healthy foods available [29]. The same principle holds true for physical activity related behaviors - that is, caregivers heavily influence their chil$\mathrm{d}(\mathrm{ren})$ 's engagement in physical activity and exercise, as well as sedentary and screen time [30]. Thus, caregivers must be involved either directly or indirectly in behavioral interventions directed at the child. The food and physical activity environments, caregivers, and peers are all targets of the Camp NERF intervention.

In sum, due to the inherent complexity of behavior, use of theoretical frameworks, such as the SEM and SCT, are absolutely critical in the design and conduct of behavioral interventions. Please refer to Fig. 1 for the Camp NERF theoretical framework.

\section{Research design}

Camp NERF is an 8-week pre-test, post-test group siterandomized controlled trial. It is a multi-component nutrition, physical activity, and mental health education intervention coupled with the USDA SFSP, specifically open sites located at public elementary schools. Through daily access to healthy foods, safe play and structured physical activity, along with engagement in an evidencebased health behavior educational curriculum, Camp NERF is designed specifically to prevent unintended, unhealthy weight gain during the summer months in underserved school-aged children. Potential sites were identified by a community partner whose responsibility it is to support SFSP sites in Franklin County, OH, and were considered eligible if they were: 1) an elementary school; 2) a USDA SFSP open site; and 3) lacking structured programming. Twelve sites were identified as meeting these inclusion criteria and will be randomized to one of three treatment or programming groups: 1) Enhanced Care (nutrition, physical activity, and mental health programming); 2) Standard Care (nutrition and physical activity programming); and 3) Active Control (non-nutrition, physical activity, and mental $4 \mathrm{H}$ 


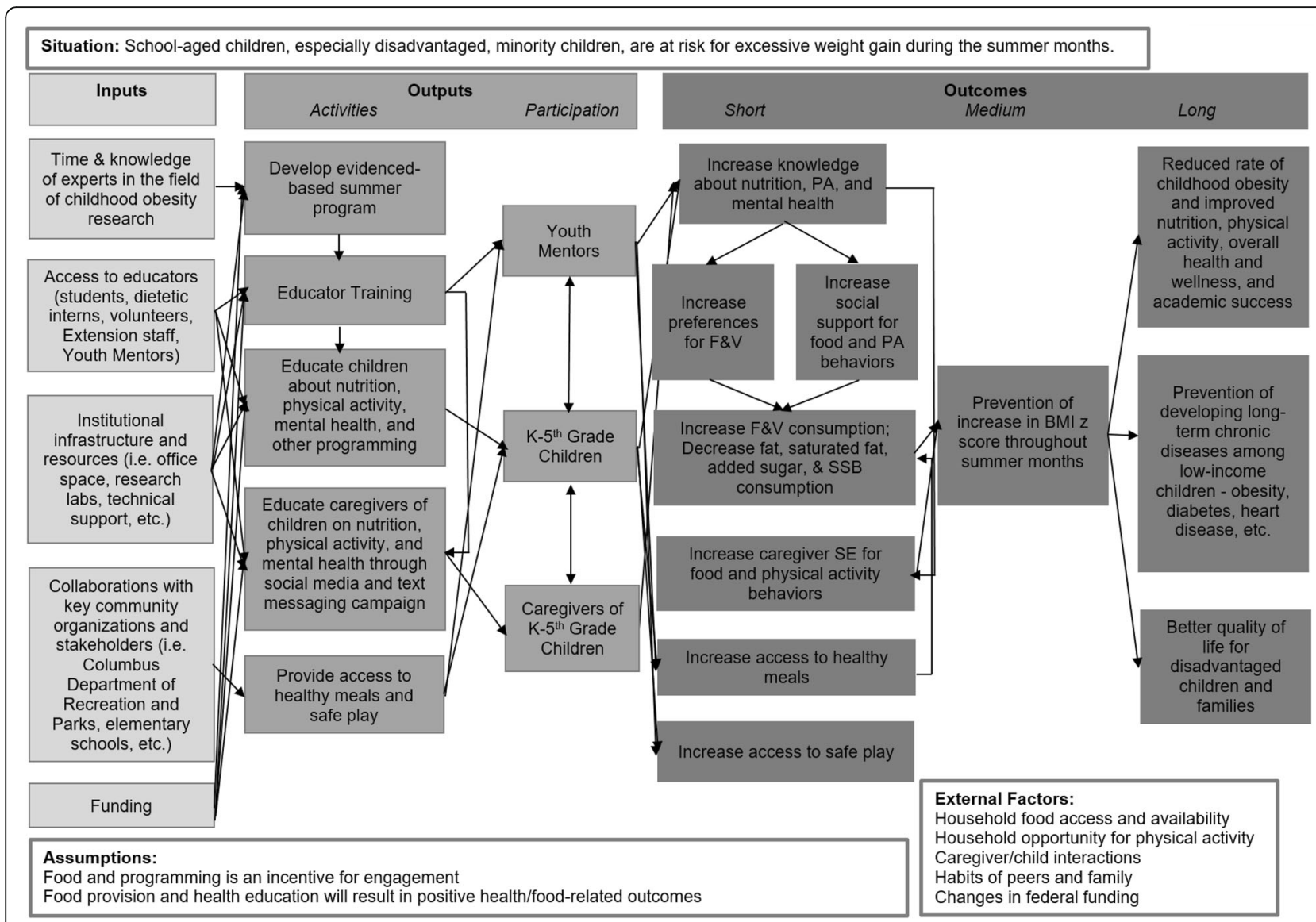

Fig. 1 Camp NERF 2015 Theoretical Framework

programming). Figure 2 provides an overview of the three treatments for Camp NERF.

Power was calculated using change in BMI z-score as the outcome of interest. Based on the results from previous pilot test [31, 32], we assume that between-subject variation is normally distributed with a standard deviation of 1.03 and that between-site variation (nested within treatment group) is negligible. Under these assumptions, recruiting 20 subjects per site (planning for $20 \%$ attrition) provides approximately $70 \%$ power to detect a difference of 0.5 points in change in BMI between the treatment group and either of the two control groups using a one-sided test at alpha $=0.05$. The model used is described further in the Data Analysis section.

USDA SFSP open feeding sites operate 5 days a week from mid-June through the beginning of August. Their hours of operation will be approximately 9:00 AM 3:00 PM, although these times vary slightly by site. Camp NERF program (Enhanced Care, Standard Care, or Active Control) will occur 2 days per week for approximately 4 hours each day. This is expected to equate to $64 \mathrm{~h}$ of direct exposure per child, a sufficient dose for eliciting behavior change in the targeted outcomes [33-42]. Table 1 provides an overview of a sample day at an Enhance Care site.

\section{Participants and recruitment}

The target population for Camp NERF is underserved minority children entering kindergarten through fifth grade and their adult caregiver from urban neighborhoods in Columbus, Ohio. Participants will be recruited through a variety of methods including, but not limited to, school announcements, emails, flyers, phone calls, and neighborhood canvassing. Prior to enrollment in the study, a consent form, parental permission form, and assent form will be completed by the caregiver and child, respectively.

Also, data will be collected from high school students who will serve as Youth Mentors for the child participants at the Camp NERF Enhanced Care sites. The Youth Mentors will be recruited through a collaborating partner, the Godman Guild Association that provides internships to high-school aged students during the summer months through Temporary Assistance for Needy Families (TANF) funding. Prior to study enrollment, a parental permission form and assent form will be 


\begin{tabular}{|c|c|c|}
\hline Active Control & Standard Care & Enhanced Care \\
\hline $\begin{array}{l}\text { - Access to free meals } \\
\text { - Access to safe play } \\
\text { - 4-H Programming }\end{array}$ & $\begin{array}{l}\text { - Access to free meals } \\
\text { - Access to safe play } \\
\text { - CATCH Nutrition } \\
\text { Education } \\
\text { - CATCH Physical } \\
\text { Education }\end{array}$ & $\begin{array}{l}\text { - Access to free meals } \\
\text { - Access to safe play } \\
\text { - CATCH Nutrition } \\
\text { Education } \\
\text { - CATCH Physical } \\
\text { Education } \\
\text { - COPE Mental Health } \\
\text { Curriculum } \\
\text { - Youth-Mentor } \\
\text { Assisted Education } \\
\text { - Caregiver Engagement }\end{array}$ \\
\hline
\end{tabular}

Fig. 2 Overview of the Camp NERF Treatments

completed by the caregiver and Youth Mentor, respectively, for those under the age of 18. Youth Mentors 18 years of age or older will complete consent forms prior to enrollment in the study. Individuals who are not interested in enrolling in the study will still be able to participate as Camp NERF Youth Mentors.

\section{Data collection}

\section{Data collection training}

Data collectors will consist of undergraduate and graduate students from nutrition, public health or other related fields, as well as registered dietitian nutritionists. All data collectors will undergo an 8-hour data collection training, which will include didactic sessions followed by role-playing to practice techniques and become familiar with the instruments. At the end of the 8week intervention prior to post-test data collection, data collectors will complete a 2-hour review training to reacquaint themselves with the instruments and learn additional post-test data collection feedback surveys.

\section{Impact measures}

Child-caregiver dyads and youth mentors will be interviewed at baseline and post-intervention using the Camp NERF Child Assessment Form, Camp NERF Adult Assessment Form, and Camp NERF Youth Mentor Assessment Form, respectively. Each assessment form consists of validated nutrition, physical activity, and mental health questionnaires. Three ( 2 weekdays and 1 weekend day) 24-hour dietary recalls will be conducted for both the children and youth mentors. Heights, weights, blood pressure, and waist circumference measurements will be taken for the children and youth mentors. Caregivers will self-report height and weight. Table 2 provides the Camp NERF Evaluation Chart and outlines all validated surveys and outcomes measured for participants.

Interviews will be conducted at the home of the participants, the site, or another community location and are estimated to take approximately $30 \mathrm{~min}, 10 \mathrm{~min}$, and $20 \mathrm{~min}$ to complete for the child, caregiver, and youth mentor, respectively. All assessment forms will be data

Table 1 Camp NERF daily curricula delivery schedule at enhanced care sites

\begin{tabular}{|c|c|c|c|}
\hline Time & Grades K-2 & Time & Grades 3-5 \\
\hline 8:30 AM & Arrival; Engage with participants before and during breakfast & $8: 30 \mathrm{AM}$ & Arrival; Engage with participants before during breakfast \\
\hline 10:00 AM & Nutrition Education & 10:00 AM & Physical Education \\
\hline 10:00 AM & Discussion & 10:00 AM & Warm-up \\
\hline 10:10 AM & Learning Activity & 10:05 AM & Go Fitness \\
\hline \multirow[t]{2}{*}{ 10:25 AM } & Physical Activity & 10:20 AM & Go Activity \\
\hline & & 10:40 AM & Cool-down \\
\hline $10: 45$ AM & Mental Health & $10: 45$ AM & Mental Health \\
\hline 11:15 AM & Physical Education & $11: 15 \mathrm{AM}$ & Nutrition Education \\
\hline 11:15 AM & Warm-up & $11: 15 \mathrm{AM}$ & Discussion \\
\hline 11:20 AM & Go Fitness & $11: 25 \mathrm{AM}$ & Learning Activity \\
\hline 11:35 AM & Go Activity & $11: 40 \mathrm{AM}$ & Physical Activity \\
\hline 11:55 AM & Cool-down & & \\
\hline 12:00 PM & Lunch; Lunchtime Engagement and Trivia & 12:00 PM & Lunch; Lunchtime Engagement and Trivia \\
\hline
\end{tabular}


Table 2 Camp NERF evaluation chart for children, caregivers, and youth mentors

\begin{tabular}{|c|c|c|c|}
\hline Outcomes & Goal & Measure & bo \\
\hline \multicolumn{4}{|l|}{ Child Outcomes } \\
\hline \multicolumn{4}{|l|}{ Nutrition } \\
\hline Food Attitudes and Preferences & Increase preference for fruits and vegetables & $\begin{array}{l}\text { Fruit and Vegetable Preferences } \\
\text { Domel } 1993^{85}\end{array}$ & $x$ \\
\hline Dietary Intake & $\begin{array}{l}\text { Increase quality of diet (increase fruit and vegetable } \\
\text { intake (quantity and variety), decrease intake of foods } \\
\text { high in solid fats and added sugars; decrease sugar- } \\
\text { sweetened beverages) }\end{array}$ & $\begin{array}{l}\text { Caregiver-assisted 24-hour diet recall } \\
\text { Burrows et al } 2010^{86} \\
\text { Baxter et al } 2003^{87} \\
\text { Baxter et al } 2009^{88}\end{array}$ & $x$ \\
\hline \multicolumn{4}{|l|}{ Physical Activity } \\
\hline $\begin{array}{l}\text { Physical activity level } \\
\text { and sedentary time }\end{array}$ & $\begin{array}{l}\text { Increase estimated active time and decrease estimated } \\
\text { time in sedentary behavior }\end{array}$ & $\begin{array}{l}\text { 3rd-5th: SPAN questionnaire } \\
\text { Hoelscher et al } 2010^{89}\end{array}$ & $x$ \\
\hline \multicolumn{4}{|l|}{ Mental Health } \\
\hline \multirow[t]{2}{*}{ Self-concept } & Increase positive affect & \multirow{2}{*}{$\begin{array}{l}\text { PANAS Survey } \\
\text { Laurent et al } 1999^{90}\end{array}$} & \multirow[t]{2}{*}{$x$} \\
\hline & Decrease negative affect & & \\
\hline
\end{tabular}

Social Support

Social Support for Food and Physical Activity Habits

Social Support for Healthy and Unhealthy Eating

Biometrics

Height and Weight

Waist Circumference

Blood Pressure

Youth Mentor Outcomes

Nutrition

Food Attitudes and Preferences

Dietary Intake

Physical Activity

Physical activity level and sedentary time

Mental Health

Self-concept

Social Support

Social Support for Food and Physical Activity Habits
Prevent increase in waist circumference

Prevent increase in blood pressure

Increase preference for fruits and vegetables

Increase quality of diet (increase fruit and vegetable intake (quantity and variety), decrease intake of foods high in solid fats and added sugars; decrease sugarsweetened beverages)

Increase estimated active time and decrease estimated sedentary time

SPAN questionnaire Hoelscher et al $2010^{89}$

PANAS Survey

Increase positive affect

Decrease negative affect

Laurent et al $1999^{90}$

Retain positive changes in self-concept

Increase social support for food and physical activity habits Lindquist et al $2000^{96}$
Social Support Scale for Food and Physical $\quad X \quad X$ Activity Habits

Gadhoke $2015^{91}$

Social Support Scale for Healthy and Unhealthy $X$ Eating

Fitzgerlad $2013^{92}$

Hopkins Road Rod Portable Stadiometer (Height)

BalanceFrom High Accuracy Digital Scale

(Weight)

2000 CDC sex-specific BMl-for-age growth chart $^{93}$

MyoTape tape measure

DC Waist Circumference Tables ${ }^{94}$

Panasonic Portable Blood Pressure Monitor NHBLI Standardized Blood Pressure Tables ${ }^{95}$

Fruit and Vegetable Preferences

Youth Mentor reported 24-hour diet recall 
Table 2 Camp NERF evaluation chart for children, caregivers, and youth mentors (Continued)

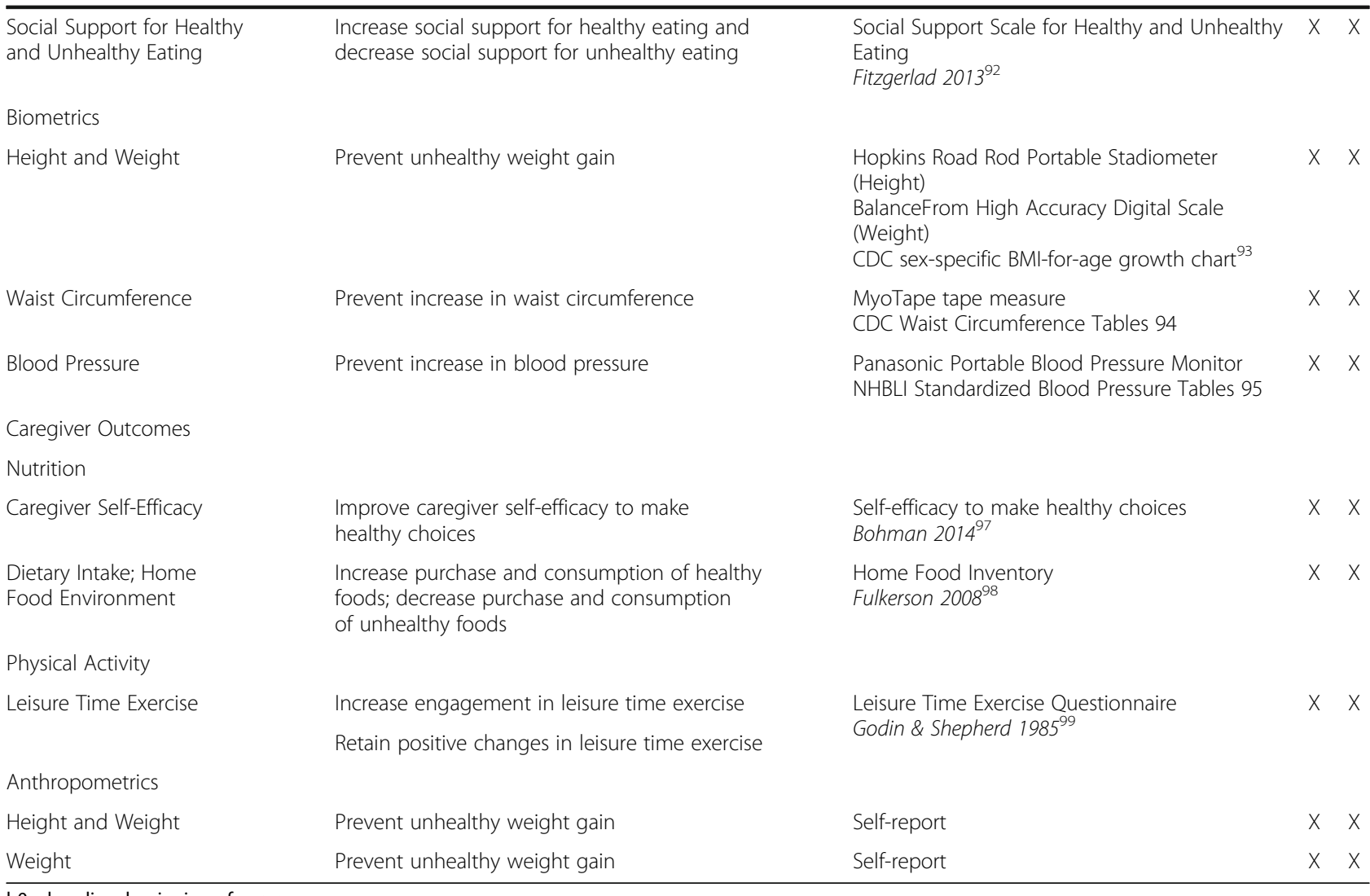

$\mathrm{b} 0$ = baseline; beginning of summer

$\mathrm{t} 1$ = post-intervention; end of summer

collector-administered, where the data collector will read each question from the assessment form verbatim including all possible responses and record the participants' response. If the participant provides an ambiguous response, the data collector will ask necessary questions to probe for a specific response. For younger children, caregivers will be asked to assist in completing and verifying responses from the child interview when deemed necessary.

\section{Data analysis}

The intervention will be tested by comparing change from baseline to post-intervention in diet quality, physical activity, mental health, and anthropometric outcomes for child participants (hypothesis 1.1) and psychosocial, physical activity, and anthropometric outcomes for adults (hypothesis 2.1). For each outcome variable of interest (Table 2), a mixed effects linear regression model will be fitted with site-type as the primary predictor. Other covariates will include race/ ethnicity, income, and attendance, as well as baseline zBMI for all models that do not include weight status as the primary outcome. Using a mixed effects linear regression model allows us to capture the contributions of two sources of variability: (1) a between-site variability and (2) a between-subject or within-site variability. Impact of Camp NERF on Youth Mentors will be tested by comparing change from baseline to post-intervention in diet quality, physical activity, mental health, and anthropometric outcomes (hypothesis 3.1) using multiple linear regression analyses.

\section{Process evaluation and environmental assessment}

A Camp NERF Site Environmental Assessment Form was developed for this study and will be completed at baseline, mid-intervention ( 4 weeks), and postintervention. The purpose of this form is to assess the demographic (i.e. predominant race/ethnicity of the staff at the sites), food environment (i.e. presence of vending machines, concession stands, and healthfulness of available foods), and physical activity environment (i.e. access to a gym, outdoor playground, equipment, etc.) characteristics of the sites. This information will be used in post-hoc analyses to determine if characteristics (i.e., access to a computer room) may have contributed to outcomes.

A Camp NERF Daily Process Evaluation Form was developed for this study and will be completed by trained 
process evaluators, who will not be involved with intervention implementation. This form assesses feasibility, fidelity, and acceptability of the intervention programming, assessment of food served, adherence to the USDA SFSP menus, and participant attendance.

\section{Intervention}

\section{Educator training and structure}

The Camp NERF counselors will be undergraduate and graduate students in fields related to nutrition, kinesiology, public health, and education. The Camp NERF counselors will complete a 3-day, 24-h training prior to the launch of Camp NERF. The training will begin with an overview of our community partners, the USDA child meal programs, other pertinent issues, e.g., underutilization of the USDA SFSP and unhealthy weight gain during the summer months. Camp NERF Counselors also will be provided with a didactic overview of each of the core components of the Camp NERF program - nutrition, physical activity, and mental health - and will be given an opportunity to practice delivery of these curricula. Additionally, they will undergo training on topics related to education delivery and necessary for work with underserved children, as well as other components of the Camp NERF intervention. Table 3 provides an overview of the Camp NERF training for the Camp Counselors. In addition to the intensive training prior to intervention launch, the Camp NERF Counselors will attend a weekly staff meeting throughout the summer to provide feedback on the lessons from the current week, to coach the staff on improvement of curricula delivery and to practice lessons for the upcoming week.

Table 3 Camp NERF counselor training overview

\begin{tabular}{ll}
\hline Day 1 & Welcome and Introductions \\
& Community Partner Overview \\
& Overview of the USDA SFSP \\
& "The Problem" and Our Place at the Table \\
& How to Keep Kids' Attention \\
& How to Identify and Report Child Abuse and Neglect \\
& CATCH Nutrition Education Overview \\
Day 2 & Practice CATCH Nutrition Education \\
& 4-H Programming Overview \\
& Practice 4-H Programming \\
& COPE Education Overview \\
& Practice COPE Education \\
& CATCH Physical Education Overview \\
& Practice CATCH Physical Education \\
& Caregiver Engagement Overview \\
& Behavioral Economics Strategies Overview \\
Day 3 & Meet and Greet with Youth Mentors
\end{tabular}

Three Camp NERF Counselors will be assigned to each site: One Counselor will serve as the kindergarten through second grade educator, one as the third through fifth grade educator, and one as the process evaluator. The Camp NERF Counselors at the Enhanced Care sites will be assisted by high school-aged adolescents - Camp NERF Youth Mentors - from the neighborhoods in which Camp NERF will be delivered.

\section{Youth mentor-assisted education}

The use of peer-led interventions have been utilized among youth in areas pertaining to the use of alcohol, tobacco, illegal drugs, violence, and sexual behavior [43-50]. Data indicate that mentored youth compared to unmentored youth are less likely to participate in these aforementioned risky behaviors [51, 52] and are more likely to succeed academically [53-56]. Until recent years, use of peers as an intervention strategy to improve nutrition and physical activity, and ultimately weight status, had not been employed, but emerging research has demonstrated positive results for biometric-, nutrition-, and physical activity-related outcomes [43, 56-68]. According to the SCT, self-efficacy is influenced by role modeling the behavior [69]. As such, the peers leading the education may experience positive behavior change as a result of child mentoring. Unfortunately, the educating of peer mentors has been understudied [56, 64, 65, 67, 68].

Youth Mentors from the neighborhoods in which Camp NERF will be implemented will be recruited and will assist in the Camp NERF education delivery at the Enhanced Care sites. The Youth Mentors will undergo a 20-h workreadiness training, as well as will attend the 2-hour weekly Camp NERF staff meetings, where feedback will be provided on the lessons for the current week and the upcoming weeks lessons will be reviewed and practiced. Additionally, professional development topics, such as how to interact with co-workers in the workplace, will be discussed in collaboration with the undergraduate- and graduate-level Camp NERF Counselors.

\section{Child education}

Nutrition and physical activity The Coordinated Approaches to Child Health (CATCH) Kid's Club Healthy Habits and Nutrition Grades K-2 and Grades 3-5 curriculum and CATCH Kid's Club Physical Education will be used for the Camp NERF nutrition and physical education components. The original CATCH program was initially implemented and evaluated from 1991-1994 in grades three through five in 96 schools in San Diego, CA, New Orleans, LA, Minneapolis, MN, and Austin, TX. Several positive findings on improvements in eating and physical activity behaviors came from these studies, including increased vigorous physical activity, decreased consumption of dietary fat, and reductions in children 
at-risk for being overweight and in children being overweight [70-74]. Due to the success of the original trial, the CATCH curriculum has continued to be adapted for and studied in various settings [75-82]. CATCH Kid's Club is the modified curriculum for the after-school setting and has been shown to be effective in improving nutrition and physical activity knowledge and behaviors and reducing overweight and obesity.

Mental Health The COPE curriculum will be the mental health component of the Camp NERF curriculum. COPE focuses on the thinking, feeling, behaving triangle and incorporates cognitive behavioral skill building in goal-setting, problem solving, coping, and emotional regulation [25]. The curriculum, originally developed for adolescents and young adults and more recently adapted to the younger audience of school-age children, consists of an introductory session and seven subsequent lessons. The lessons will be introduced and taught on the first day of Camp NERF each week, and the skills practice and review of lesson will be completed on the second day of Camp NERF each week.

4H Programming In order to assess whether potential differences demonstrated between participants is due to the type of programming delivered, as opposed to mere exposure to daily structured programming, an active control group was chosen for Camp NERF. Thus, the Camp NERF research team worked closely with 4-H Extension Specialists to identify non-nutrition and physical activity related programming suited for our target population. Sixteen lessons from the Cloverbud [83] curriculum will be delivered to participants at the Active Control sites.

\section{Caregiver engagement}

The caregiver engagement component will be in the form of a texting program that will utilize a mass messaging platform, social media (Facebook and Instagram), and traditional education materials. Adult caregivers of Camp NERF participants in the Enhanced Care group will be provided the option to receive three text messages each week over the course of the intervention. The first message each week will introduce the main nutrition topic that was presented to their child during programming but will encourage completion of a specific family nutrition goal to be attained by the end of the week. For example, the message preceding the fourth week of programming may read as follows: "Today at Camp NERF, your child learned about healthy fast food items. Are you in for trying healthier items at fast food restaurants? Please reply with 'Yes' or 'No'." The second message content will consist of either a strategy to assist the caregivers in reaching the weekly goal or educational information related to the topic of the week. The final message will inquire about achievement of the goalsetting challenge proposed at the start of the week.

Social media outlets such as Facebook, Twitter, and Instagram will be offered as an alternative means for caregivers to receive insight on the nutrition topic for the week. Images or videos will be added to the websites for caregivers to view and interact with counselors as well as other caregivers. Nutrition topics will be explored in greater depth, such as links to simple food recipes, news items, and recent educational articles related to the weekly topic.

In addition to the text-messaging and social media campaigns, traditional educational materials also will be disseminated to caregivers at the Enhanced Care sites weekly. These educational materials are adapted from the CATCH Kids Club Healthy Habits and Nutrition curriculum handouts for parents [26]. The handouts are modified to include concepts from the CATCH Physical Education curriculum and the COPE curriculum [26, 27]. Child participants will be given handouts at the end of the week to take home to their caregivers.

\section{Discussion}

Despite the recent plateauing in prevalence, the number of obese children remains high, which is problematic due to the negative, short- and long-term health consequences for children [1-3]. Emerging research has indicated the summertime as a particular window of risk for unhealthy weight gain among children, especially underserved, minority children [4-10]. Few efforts have been directed at designing evidence-based nutrition and physical activity programs to equip children with the necessary knowledge, skills, and other resources to prevent excess weight gain during the summer recess.

The purpose of this paper is to describe the aims and research methods of Camp NERF, a multi-component, evidence-based nutrition, physical activity, and mental health intervention coupled with USDA SFSP open sites in Columbus, Ohio to address the disproportionate childhood weight gain in underserved children during the summer months. To our knowledge, Camp NERF is the first evidenced-based nutrition education research study and program to address this issue. This study will fill a critical research void and provide insight for effective programming to address child health during the summer months. The Camp NERF program is coupled with the USDA SFSP and utilized existing systems for implementation, which ensures the future sustainability of the program.

Several challenges or limitations have been identified. Engagement from caregivers in the target population may be a challenge, as it is a common issue with intervention research involving underserved families [84, 85]. 
However, this study was developed and designed to overcome this barrier. The research team and community collaborators will be present in the participating neighborhoods for several years throughout the development of the project. High-school aged students from the intervention communities will be engaged as Youth Mentors and will assist with education delivery throughout the entirety of the program. Traditional (educational handout materials) and innovative (text messaging and social media) strategies will be utilized to inform parents about the programming and encourage participation. Another limitation is the lack of a true negative control group. Because Camp NERF will be coupled with the USDA SFSP, a federal child nutrition program, the statutory right for participation applies. Ethically, the research team cannot ask children and families to not participate at the open SFSP sites. Additionally, recruitment methods are not designed to seek participants who do not intend to attend the SFSP sites during the summer.

In summary, Camp NERF builds on successful childhood obesity prevention interventions which include nutrition and physical activity components, concurrent knowledge and skill building, coupling of the intervention curriculum to availability of healthy foods, and opportunity for physical activity and play $[18,86]$. Studying the impact of such an intervention over the summer months will provide valuable information in tackling a time period during which children may be at increased risk for excessive weight gain.

\section{Acknowledgements}

We thank our community collaborators, particularly Children's Hunger Alliance, Columbus Recreation and Parks Department, and the Godman Guild Association.

\section{Funding}

The Aetna Foundation.

\section{Availability of data and material}

Not applicable.

\begin{abstract}
Authors' contributions
CG led the conceptual development of the study with input from LCH, BM, $J D G, M F$, IE, and JAK. LCH and CG led intervention preparations with assistance from JDG, BM, MF, JAK, and IE. LCH and CG took primary responsibility for writing the manuscript. IE, JDG, JAK, MF, and BM contributed to editing the manuscript. CG, LCH, MF, JDG, IE, JAK, and BM read and approved the final manuscript. All authors read and approved the final manuscript.
\end{abstract}

\section{Competing interests}

The authors declare that they have no competing interests.

\section{Consent for publication}

Not applicable.

\section{Ethics approval and consent to participate}

This study was approved by The Ohio State University Behavioral and Socia Sciences Institutional Review Board. Parent consent and parent permission, as well as child assent will be received from participants prior to study enrollment.

\section{Author details}

'Department of Human Sciences, Human Nutrition Program, The Ohio State University, 262B Campbell Hall, 1787 Neil Avenue, Columbus, OH 43210, USA. ${ }^{2}$ Department of Psychiatry and Behavioral Health, The Ohio State University Wexner Medical Center, 1670 Upham Drive Suite 460G, Columbus, OH 43210-1250, USA. ${ }^{3}$ Department of Human Sciences, Kinesiology Program, College of Education \& Human Ecology, The Ohio State University, A244 305 Annie \& John Glenn Ave, Columbus, OH 43210, USA. ${ }^{4}$ Nationwide Children's Hospital; The Ohio State University, 700 Children's Drive, Columbus, OH 43205, USA. ${ }^{5}$ Department of Statistics, The Ohio State University, 404 Cockins Hall, 1958 Neil Ave, Columbus, OH 43210, USA. ${ }^{6}$ Department of Human Sciences, Human, The Ohio State University, 315 Campbell Hall, 1787 Neil Avenue, Columbus, OH 43210, USA. ${ }^{7}$ College of Nursing, The Ohio State University, 1585 Neil Avenue, Rm. 145, Columbus, OH 43210, USA.

${ }^{8}$ Department of Human Sciences, Human Nutrition Program, The Ohio State University, 313 Campbell Hall, 1787 Neil Avenue, Columbus, OH 43210, USA.

Received: 4 August 2016 Accepted: 12 October 2016

Published online: 26 October 2016

\section{References}

1. Ogden $\mathrm{CL}$, Carroll MD, Kit BK, Flegal KM. Prevalence of childhood and adult obesity in the United States, 2011-2012. JAMA. 2014;311(8):806-14.

2. Halfon N, Larson K, Slusser W. Associations between obesity and comorbid mental health, developmental, and physical health conditions in a nationally representative sample of US children aged 10 to 17. Acad Pediatr. 2013;13(1):6-13.

3. Taras H, Potts-Datema W. Obesity and student performance at school. J Sch Health. 2005;75(8):291-5.

4. von Hippel PT, Powell B, Downey DB, Rowland NJ. The effect of school on overweight in childhood: gain in body mass index during the school year and during summer vacation. Am J Public Health. 2007;97(4):696-702.

5. Moreno JP, Johnston CA, Woehler D. Changes in Weight Over the School Year and Summer Vacation: Results of a 5-Year Longitudinal Study. J Sch Health. 2013:83(7):473-7.

6. Moreno JP, Johnston CA, Chen T-A, et al. Seasonal variability in weight change during elementary school. Obesity (Silver Spring). 2015;23(2):422-8.

7. Kobayashi M, Kobayashi M. The relationship between obesity and seasonal variation in body weight among elementary school children in Tokyo. Econ Hum Biol. 2006;4(2):253-61.

8. Smith DT, Bartee RT, Dorozynski CM, Carr LJ. Prevalence of overweight and influence of out-of-school seasonal periods on body mass index among American Indian schoolchildren. Prev Chronic Dis. 2009;6(1):A20.

9. Baranowski T, O'Connor T, Johnston C, et al. School year versus summer differences in child weight gain: a narrative review. Child Obes. 2014;10(1): $18-24$.

10. Franckle R, Adler R, Davison K. Accelerated weight gain among children during summer versus school year and related racial/ethnic disparities: a systematic review. Prev Chronic Dis. 2014;1 1(12):1-10.

11. Tovar A, Lividini K, Economos CD, Folta S, Goldberg J, Must A. School's out: what are urban children doing? The Summer Activity Study of Somerville Youth (SASSY). BMC Pediatr. 2010;10:16.

12. Sallis JF, Glanz K. Physical activity and food environments: solutions to the obesity epidemic. Milbank Q. 2009;87(1):123-54.

13. Swinburn BA, Sacks G, Hall KD, et al. The global obesity pandemic: shaped by global drivers and local environments. Lancet. 2011;378(9793):804-14.

14. Briefel RR, Crepinsek MK, Cabili C, Wilson A, Gleason PM. School food environments and practices affect dietary behaviors of US public school children.J Am Diet Assoc. 2009:109(2 Suppl):S91-S107.

15. United States Department of Agriculture Food and Nutrition Service. Summer Food Service Program. http://www.fns.usda.gov/sfsp/sfsp-mealsand-snacks. Accessed 12 Apr 2015.

16. Food Research Action Center. Federal Nutrition Programs. 2013. http://frac. org/federal-foodnutrition-programs/.

17. Food Research and Action Center. Hunger Doesn't Take a Vacation: Summer Nutrition Status Report. 2016. p. 1-20.

18. Contento I, Balch $\mathrm{G}$, Bronner $\mathrm{Y}$, et al. The effectiveness of nutrition education and implications for nutrition education policy, programs, and research: A review of research. J Nutr Educ. 1995;27:280-319.

19. Bronfenbrenner U. Ecology of the family as a context for human development: research perspectives. Dev Psychol. 1986;22:723-42. 
20. Bandura A. Social Foundations of Thought and Action a Social Cognitive Theory. Engelwood: Prentice Hall; 1986.

21. Bandura A. Human agency in social cognitive theory. Am Psychol. 1989; 44(9):1175-84

22. Lytle LA, Seifert S, Greenstein J, McGovern P. How do children's eating patterns and food choices change over time? Results from a cohort study. Am J Health Promot. 2000;14(4):222-28.

23. Melnyk BM, Jacobson D, Kelly S, O'Have J, Small L, Mays M. Improving the Mental Health, Healthy Lifestyle Choices, and Physical Health of Hispanic Adolescents: a randomized controlled pilot study. J Sch Health. 2009;79(12):575-84.

24. Kelly S, Melnyk BM, Belyea M. Predicting physical activity and fruit and vegetable intake in adolescents: a test of the information, motivation, behavioral skills model. Res Nurs Health. 2012;35(2):146-63.

25. Zabinski MF, Daly T, Norman GJ, et al. Psychosocial correlates of fruit, vegetable, and dietary fat intake among adolescent boys and girls. J Am Diet Assoc. 2006;106(6):814-21.

26. Luton S, Berry J. CATCH Kids Club Healthy Habits \& Nutrition: An AfterSchool Curriculum for Grades K-5. Hasbrouck Heights: FlagHouse, Inc.; 2011.

27. Melnyk BM. Creating Opportunities for Personal Empowerment: a 7-Session Cognitive Behavioral Skills Builidng Program for Children. Powell: Cope2Thrive, LLC: 2015.

28. Bluford D a a, Sherry B, Scanlon KS. Interventions to prevent or treat obesity in preschool children: a review of evaluated programs. Obesity (Silver Spring). 2007;15(6):1356-72

29. Pearson N, Biddle SJH, Gorely T. Family correlates of fruit and vegetable consumption in children and adolescents: a systematic review. Public Health Nutr. 2009;12(2):267-83.

30. Gustafson SL, Rhodes RE. Parental correlates of physical activity in children and early adolescents. Sport Med. 2006;36(1):79-97.

31. Hopkins LC, Rose A, Gunther C. Camp NERF: Feasibility, Acceptability, and Potential Efficacy of a Theory-Based Nutrition Education Recreation and Fitness Program Aimed at Preventing Unhealthy Weight Gain in Disadvantaged Children during Summer Months. FASEB J. 2015;29:911.6.

32. Hopkins LC, Rose A, Higgins E, Gunther C. Methods and Fidelity of a Nutrition Education Recreation and Fitness Program to Prevent Child Weight Gain during Summer. J Nutr Educ \& Behav 2015;47:S34.

33. Boylan $\mathrm{K}$, Macpherson $\mathrm{H}$ a, Fristad $\mathrm{M}$ a. Examination of disruptive behavior outcomes and moderation in a randomized psychotherapy trial for mood disorders. J Am Acad Child Adolesc Psychiatry. 2013;52(7):699-708.

34. Contento IR, Manning AD, Shannon B. Research perspective on schoolbased nutrition education. J Nutr Educ. 1992;24(5):247-60.

35. Fristad M, Verducci J, Walters K, Young M. The impact of multi-family psychoeducational psychotherapy in treating children aged 8-12 with mood disorders. Arch Gen Psychiatry. 2009;66(9):1013-21.

36. Goodway JD, Branta CF. Influence of a motor skill intervention on fundamental motor skill development of disadvantaged preschool children. Res Q Exerc Sport. 2003;74(1):36-46.

37. Goodway JD, Crowe H, Ward P. Effects of Motor Skill Instruction on Fundamental Motor Skill Development. Adapt Phys Act Q. 2003:20;298-314.

38. Kim JS. Effects of a voluntary summer reading intervention on reading achievement: results from a randomized field trial. Educ Eval Policy Anal. 2006; 28(4):335-55

39. Lusk P, Melnyk BM. COPE for depressed and anxious teens: a brief cognitive-behavioral skills building intervention to increase access to timely, evidence-based treatment. J Child Adolesc Psychiatr Nurs. 2013;26(1):23-31.

40. Melnyk BM, Jacobson D, Kelly S, et al. Promoting healthy lifestyles in high school adolescents: a randomized controlled trial. Am J Prev Med. 2013;45(4):407-15.

41. Robinson LE, Rudisill ME, Goodway JD. Instructional climates in preschool children who are at-risk. Part II: perceived physical competence. Res Q Exerc Sport. 2009;80(3):543-51.

42. Rose AM, Wagner AK, Kennel JA, et al. Determining the feasibility and acceptability of a Nutrition Education and Cooking Program for preschoolers and their families delivered over the dinner hour in a lowincome day care setting. Infant, Child Adolesc Nutr. 2014;6(3):144-51.

43. Birnbaum AS, Lytle L a, Story M, Perry CL, Murray DM. Are differences in exposure to a multicomponent school-based intervention associated with varying dietary outcomes in adolescents? Health Educ Behav. 2002;29(4):427-43

44. Black DR, Tobler NS, Sciacca JP. Peer helping/involvement: an efficacious way to meet the challenge of reducing alcohol, tobacco, and other drug use among youth? J Sch Health. 1998;68(3):87-93.
45. Fors SW, Jarvis S. Evaluation of a Peer-Led Drug Abuse Risk Reduction Project for Runaway/homeless Youths. J Drug Educ. 1995;25(4):321-33.

46. Klepp Kl, Halper A, Perry CL. The efficacy of peer leaders in drug abuse prevention. J Sch Health. 1986:56(9):407-11.

47. Komro KA, Perry CL, Murray DM, Veblen-Mortenson S, Williams CL, Anstine PS. Peer-planned social activities for preventing alcohol use among young adolescents. J School Health. 1996;66(9):328-44.

48. Orpinas P, Parcel GS, McAlister A, Frankowski R. Violence prevention in middle schools: a pilot evaluation. J Adol Health. 1995;17(6):360-71.

49. Perry CL. Prevention of alcohol use and abuse in adolescence: teacher- vs peer-led intervention. Crisis. 1989;10(1):52-61.

50. Sawyer RG, Pinciaro P, Bedwell D. How peer education changed peer sexuality educators' self-esteem, personal development, and sexual behavior. J Am Coll Health. 1997;45(5):211-7.

51. Beier SR, Rosenfeld WD, Spitalny KC, Zansky SM, Bontempo AN. The potential role of an adult mentor in influencing high-risk behaviors in adolescents. Arch Pediatr Adolesc Med. 2000;154(4):327-31.

52. Zimmerman MA, Bingenheimer JB, Notaro PC. Natural mentors and adolescent resiliency: a study with urban youth. Am J Community Psychol. 2002;30(2):221-43

53. DuBois $\mathrm{DL}$, Silverthorn N. Natural mentoring relationships and adolescent health: evidence from a national study. Am J Public Health. 2005;95(3):51824.

54. Klaw EL, Rhodes JE. Mentor relationships and the career development of pregnant and parenting African-American teenagers. Psychol Women Q. 1995;19(4):551-62.

55. Rhodes JE, Grossman JB, Resch NL. Agents of change: pathways through which mentoring relationships influence adolescents' academic adjustment. Child Dev. 2000;71(6):1661-71.

56. Black MM, Arteaga SS, Sanders J, et al. College mentors: a view from the inside of an intervention to promote health behaviors and prevent obesity among low-income, urban, African American adolescents. Health Promot Pract. 2012;13(2):238-44

57. Black MM, Hager ER, Le K, et al. Challenge! Health promotion/obesity prevention mentorship model among urban, black adolescents. Pediatrics. 2010;126:280-8.

58. Lo E, Coles R, Humbert ML, Polowski J, Henry CJ, Whiting SJ. Beverage intake improvement by high school students in Saskatchewan, Canada. Nutr Res. 2008;28:144-50.

59. Cawley J, Cisek-Gillman L, Roberts R, et al. Effect of HealthCorps, a high school peer mentoring program, on youth diet and physical activity. Child Obes. 2011;7(5):364-71.

60. Dowd AJ, Chen MY, Jung ME, Beauchamp MR. "Go Girls!": psychological and behavioral outcomes associated with a group-based healthy lifestyle program for adolescent girls. Transl Behav Med. 2015;5(1):77-86.

61. Spencer R, Bower J, Kirk SFL, Hancock Friesen C. Peer Mentoring Is Associated With Positive Change in Physical Activity and Aerobic Fitness of Grades 4, 5, and 6 Students in the Heart Healthy Kids Program. Health Promot Pract. 2014:15:803-11.

62. Smith LH. Piloting the use of teen mentors to promote a healthy diet and physical activity among children in Appalachia. J Spec Pediatr Nurs. 2011; 16(1):16-26

63. Perry $\mathrm{CL}$, Klepp K-I, Halper A, et al. Promoting healthy eating and physical activity patterns among adolescents: a pilot study of "Slice of Life". Heal Educ Res. 1987:2(2):93-103.

64. Bogart LM, Elliott MN, Uyeda K, Hawes-Dawson J, Klein DJ, Schuster MA. Preliminary healthy eating outcomes of SNaX, a pilot community-based intervention for adolescents. J Adolesc Health. 2011;48(2):196-202.

65. Hamdan S, Story M, French S a, Fulkerson J a, Nelson H. Perceptions of adolescents involved in promoting lower-fat foods in schools: associations with level of involvement. J Am Diet Assoc. 2005;105:247-51.

66. Lytle L, Murray DM, Perry CL, et al. School-based approaches to affect adolescents' diets: results from the TEENS study. Health Educ Behav. 2004; 31(2):270-87.

67. Story $M, L y t l e ~ L a$, Birnbaum AS, Perry CL. Feasibility and process evaluation of the TEENS Study. J Sch Health. 2002;72:121-7.

68. Stock S, Miranda C, Evans S, et al. Healthy Buddies: a novel, peer-led health promotion program for the prevention of obesity and eating disorders in children in elementary school. Pediatrics. 2007;120(4):e1059-68.

69. Bandura A. Health promotion by social cognitive means. Health Educ Behav. 2004;31:143-64. 
70. Nader PR, Stone EJ, Lytle LA, et al. Three-year maintenance of improved diet and physical activity: the CATCH Cohort. Child and adolescent trial for cardiovascular health. JAMA Ped. 1999;151(7):695-704.

71. Coleman J, Tiller C, Sanchez J, et al. Prevention of the epidemic increase in child risk of overweight in low-income schools: the El Paso coordinated approach to child health. Am J Heal Promot. 2008;22(4):217-24.

72. Luepker RV, Perry CL, McKinlay SM, et al. Outcomes of a field trial to improve children's dietary patterns and physical activity. The Child and Adolescent Trial for Cardiovascular Health. CATCH Collaborative Group. JAMA. 1996;275(10):768-76.

73. Hoelscher DM, Mitchell P, Dwyer J, Elder J, Clesi A, Snyder P. How the CATCH eat smart program helps implement the USDA regulations in school cafeterias. Health Educ Behav. 2003;30(4):434-46.

74. Hoelscher DM, Kelder SH, Pérez A, et al. Changes in the regional prevalence of child obesity in 4th, 8th, and 11th grade students in Texas from 20002002 to 2004-2005. Obesity (Silver Spring). 2010;18(7):1360-8.

75. Kelder S, Hoelscher DM, Barroso CS, Walker JL, Cribb P, Hu S. The CATCH Kids Club: a pilot after-school study for improving elementary students' nutrition and physical activity. Public Health Nutr. 2005;8(2):133-40.

76. Dzewaltowski DA, Rosenkranz RR, Geller KS, et al. HOP'N after-school project: an obesity prevention randomized controlled trial. Int J Behav Nutr Phys Act. 2010;7:90

77. Slusser WM, Sharif MZ, Erausquin JT, Kinsler JJ, Collin D, Prelip ML. Improving overweight among at-risk minority youth: results of a pilot intervention in after-school programs. J Health Care Poor Underserved. 2013;24(2 Suppl):12-24.

78. Werner D, Teufel J, Holtgrave PL, Brown SL. Active generations: an intergenerational approach to preventing childhood obesity. J Sch Health. 2012;82(8):380-6.

79. Han J, McGaugh M. Oklahoma CATCH Kids Club: 2010 Analysis; 2009.

80. Hans J, McGaugh M. Oklahoma CATCH Kids Club: 2011-2012 Analysis; 2011.

81. Sharpe E, Forrester S, Mandigo J, Delion S. Evaluation of CATCH Kinds Club in Ontario after-School Programs: Final Report; 1999.

82. Conroy J. Evaluation of Healthy U: After School, Year 5 Executive Summany; 2002.

83. Banbury-Robinson J. Ohio's 4H Cloverbud Program. Columbus: The Ohio State University Extension; 1999.

84. Corbie-Smith G, Thomas S, St George D. Distrust, race, and research. Arch Intern Med. 2002;162:2458-63.

85. Goode TD, Harrison S. Policy Brief 3: Cultural competence in primary health care: partnerships for a research agenda. Washington: National Center for Cultural Competence, Georgetown University Child Development Center, Center for Child Health and Mental Health Policy-University Affiliated Program; 2000 Summer.

86. Katz DL, O'Connell $\mathrm{M}$, Yeh M-C, et al. Public health strategies for preventing and controlling overweight and obesity in school and worksite settings: a report on recommendations of the Task Force on Community Preventive Services. MMWR Recomm Rep. 2005;54(RR-10):1-12.

\section{Submit your next manuscript to BioMed Central and we will help you at every step:}

- We accept pre-submission inquiries

- Our selector tool helps you to find the most relevant journal

- We provide round the clock customer support

- Convenient online submission

- Thorough peer review

- Inclusion in PubMed and all major indexing services

- Maximum visibility for your research

Submit your manuscript at www.biomedcentral.com/submit

Biomed Central 